\title{
Atenção humanizada ao recém-nascido de baixo peso - Método Canguru: a proposta brasileira
}

\author{
H umanization in low weight newborn \\ intensive care - Kangaroo M other Care: \\ the Brazilian propose
}

\author{
Zeni Carvalho Lamy 1 \\ M aria A uxiliadora de S. M endes Gomes 2 \\ Nicole Oliveira M ota Gianini 2 \\ Márcia de Abreu e S. Hennig 3
}

A bstract This work describes the start of Kangaroo Care utilization in Colombia, his spread in other countries and how it is applied in Brazil, contextualizing the Brazilian experience in the H umanized Care of Low Weight N ewborn - Kangaroo Care (AHRNPB-MC). O ur primary source to systemize the experience was the analysis of documents, including official papers produced by the Brazilian health department. The study provided a reflection on the AHRN PB-M C and his use as tool for improvement the Brazilian neonatal care.

Key words Humanized care, Neonatal assistance, Public health, Kangaroo Care
Resumo Este estudo contextualiza a experiência brasileira na Atenção Humanizada ao RecémNascido de Baixo Peso-M étodo C anguru, resgatando aspectos ligados à origem do M étodo Canguru na Colômbia e sua utilização em diferentes países. Para sistematizar a experiência partiu-se da leitura de fontes diversas que incluíram artigos, di ssertações, teses e textos oficiais produzidos pelo M inistério da Saúde. A análise do processo de implantação da Atenção H umanizada ao Recém- $\mathrm{N}$ asci do de Baixo Peso - M étodo Canguru pelo M inistério da Saúde nos permitiu mapear uma experiência distinta da encontrada em países que adotaram ou discutem o M étodo Canguru como estratégia de substituição de tecnologia. Por outro lado, a experiência brasileira também é mais ampla do que aquela encontrada nos países desenvolvidos e se configura como estratégia de qualificação do cuidado neonatal.

Palavras-chave Humanização, Assistência neonatal, Política pública de saúde, M étodo Canguru

\footnotetext{
1 H ospital Universitário, UFMA.

Rua 11 Quadra-E Casa-13, Jardim Coelho Neto, Calhau, 65071-430, São Luís M A. lamy@elo.com.br 2 IFF/Fiocruz e Secretaria Municipal de Saúde do Rio de Janeiro. 3 Hospital Central da Polícia Militar do Rio de Janeiro.
} 


\section{Introdução}

O M étodo Canguru é um tipo de assistência neonatal voltada para 0 atendimento do recémnascido prematuro que implica colocar o bebê em contato pele a pele com sua mãe (OMS, 2004). A sua criação, em Bogotá, na Colômbia, surgiu da busca de uma solução imediata para a superlotação das unidades neonatais nas quais muitas vezes se encontravam dois ou mais recém-nascidos em uma mesma incubadora (Charpak, 1999).

A partir dessa experiência, no entanto, estudos subseqüentes apontaram que a presença contínua da mãe junto do bebê, além de garantir calor e leite materno, trazia inúmeras outras vantagens dentre as quais a promoção do vínculo mãe-bebê, condição indispensável para a qualidade de vida e sobrevivência do recémnascido após a alta da U nidade N eonatal.

Ao longo das três últimas décadas o M étodo Canguru vem despertando grande interesse dentre os profissionais envolvidos na assistência neonatal em todo o mundo, sendo cada vez mais utilizado, sem que exista, entretanto, uma diretriz única. São diversas as formas utilizadas em sua aplicação no que diz respeito à abrangência, ao tempo de início e ao tempo de permanência na posição canguru.

Essa disseminação tem tomado dois caminhos. 0 método continua sendo recomendado como alternativa para países muito pobres que não dispõem de uma boa organização neonatal (Charpak, 2001; OM S, 2004). M as vem sendo muito utilizado, também, por países desenvolvidos, que contam com todos os recursos necessários para a assistência neonatal (Browne, 2005).

No Brasil, hoje, mesmo aqueles profissionais que não utilizam o método em seus serviços e até os que fazem restrições a ele têm buscado compreender melhor a proposta nacional de utilização que foge da perspectiva de substituição de incubadora, utilizando o M étodo Canguru como mais uma tecnologia disponível para o cuidado do bebê internado em terapia intensiva neonatal.

Desta forma o M étodo Canguru abrange questões como os cuidados técnicos com o bebê (manuseio, atenção às necessidades individuais, cuidados com luz, som, dor); 0 acolhimento à família; a promoção do vínculo mãe/ bebê e do aleitamento materno; e o acompanhamento ambulatorial após a alta.

Foi sob essa perspectiva de minimizar os efeitos negativos da internação neonatal sobre os bebês e suas famílias que a Área da Criança do M inistério da Saúde adotou o M étodo Canguru como uma Política Nacional de Saúde, inserido no contexto da humanização da assistência neonatal. A N orma de Atenção H umanizada ao Recém- $N$ ascido de Baixo Peso - M étodo Canguru foi lançada em dezembro de 1999.

Para compreendermos a trajetória do M étodo Canguru como Política N acional de Saúde, no Brasil, énecessário destacar que a humanização no ambiente da U nidade de Terapia Intensiva N eonatal (UTIN) éuma questão de importância crescente na qualidade da atenção ao recém-nascido. Portanto, humanização e qualidade da assistência não podem ser vistas como fenômenos dissociados.

Essa ampliação do olhar sobreo método foi de fundamental importância para a sua disseminação no Brasil. Entretanto, outros dois fenômenos também estão inseridos nesse contexto. Primeiro, o crescente reconhecimento, por parte das equipes de neonatologia, da importância dos cuidados maternos para a recuperação dos bebês e, em segundo lugar, o momento atual no qual a humanização da assistência tem sido apresentada como política nacional do M inistério da Saúde.

Todos os anos nascem no mundo $20 \mathrm{mi}$ Ihões de recém-nascidos de baixo peso, muitos em conseqüência de um parto prematuro. Isso contribui de maneira substancial para a elevada taxa de mortalidade neonatal ainda existente em várias regiões, principalmente nos países pobres (OM S, 2004). No Brasil, desde o início da década de 1990, a M ortalidade N eonatal passou a ser o principal componente da M ortalidade Infantil, em função, principalmente, da redução proporcional de óbitos pós-neonatais e da manutenção do componente neonatal precoce (Lansky et al., 2002).

Essa maior visibilidade dos óbitos neonatais em nosso meio, decorrente até mesmo da mel horia dos sistemas de informação, condicionou a inclusão da assistência obstétrica e neonatal, em seus diferentes níveis de complexidade, na agenda de prioridades das políticas de saúde nos três âmbitos de gestão do nosso sistema de saúde (Gomes, 2004).

Embora a redução da morbimortalidade neonatal esteja atrelada a uma série de intervenções que buscam a melhoria das condições do pré-natal e da atenção ao parto e nascimento, uma intervenção que se mostrou relevante nos últimos anos foi a implantação de leitos neonatais capazes de aten der recém-natos de 
baixo peso, prematuros e/ou gravemente enfermos (Gomes, 2002).

A necessidade de ampliação de leitos para atendimento de recém-nascidos de risco torna indispensável uma maior compreensão do ambiente de internação neonatal. N esse contexto, temos observado a crescente produção de estudos sobre as especificidades desse período e do impacto do ambiente da terapia intensiva sobre 0 desenvolvimento infantil nas múltiplas dimensões da vida futura do bebê e sua família (Lamy, 2000; Santoro \& Santoro, 2002).

Os trabal hos pioneiros de Klaus \& Kennell (2000), destacando a importância dos cuidados maternos para o mel hor desenvolvimento do bebê, chamam a atenção para os efeitos que a separação precoce e prolongada entre mãe e bebê podem trazer como fator de risco para atraso no desenvolvimento e seqüelas neurológicas.

Neste artigo discutimos a experiência brasileira com o M étodo Canguru no contexto da humanização da assi stência neonatal, visando apresentar as diferenças de concepção em relação a outros países.

\section{Estratégia metodológica}

Para alcançar o objetivo de discutir a proposta brasileira, partiu-se de uma análise documental com fontes que incluem textos oficiais produzidos pelo M inistério da Saúde, publicações de autores que discutem o M étodo Canguru e a humanização, bem como resultados de dissertações e teses acadêmicas nessas áreas.

Foram pesquisadas as bases de dados $\mathrm{Me}$ dline, Lilacs e SciELO, na busca de artigos que descrevessem ou anal isassem estratégias de humanização da assistência neonatal e modelos de utilização do M étodo Canguru em diferentes contextos, tendo sido encontrados 96 artigos. 0 conhecimento sobre o panorama do M étodo Canguru em outros países foi também obtido através dos relatos de experiências por ocasião dos encontros mundiais voltados para a discussão dessa temática (International Workshop on Kangaroo M other Care).

\section{H istórico do Método C anguru}

O M étodo $M$ ãe-Canguru ( $M$ M C) foi criado em 1978 pelo dr. Edgar Rey Sanabria, no Instituto M aterno-Infantil (IMI) de Bogotá, na Colômbia. 0 método consistia em colocar o bebê entre os seios maternos, em contato pele a pele, na posição supina (postura preventiva para refluxo gastroesofágico e aspiração pulmonar). Desta forma, mantendo-se aquecidos com o calor do corpo de sua mãe, os bebês poderiam sair mais cedo da incubadora e, conseqüentemente, ir mais cedo para casa, minimizando um grave problema da época: superlotação e infecção.

Além dessas vantagens, observou-se, desde o início, que o contato pele a pele precoce e duradouro entre a mãe e o seu filho também favorecia a formação de vínculos afetivos e um melhor desenvolvimento do bebê, o que despertou interesse do Unicef por pesquisas e observações desta nova prática. 0 trabalho inicial teve continuidade com o dr. Hector $\mathrm{M}$ artinez Gómez e, posteriormente, com o dr. Luis Navarrete Pérez, médicos pediatras da mesma instituição colombiana (Charpak et al., 1999).

Em 1993 as pediatras dra. N athalie Charpak e dra. Zita Figueroa implantaram o Programa $\mathrm{M}$ ãe-Canguru na Clínica del $\mathrm{Niño}$ do Instituto de la Seguridad Social (ISS) da Colômbia, com a colaboração de um grupo multiprofissional. Reunido na Fundação Canguru, que conta com o apoio de uma ONG suíça (World Laboratory) e da U nión Europea (EED), o grupo difundiu a técnica, realizando também muitas pesquisas para estudo do M étodo.

$\mathrm{Na}$ Colômbia, o programa é predominantemente ambulatorial, com especial ênfase em um rigoroso acompanhamento do crescimento e desenvolvimento do bebê (Botero, 2000). 0 M étodo Canguru é praticado no domicílio materno, inicialmente com acompanhamento diário no ambulatório de seguimento - Casita Canguro.

$\mathrm{Na}$ Colômbia não existe uma U nidade Canguru hospitalar onde mães e bebês possam permanecer juntos diuturnamente. A fase hospitalar do método tem como objetivo principal preparar a díade para a prática domiciliar. N esse período, denominado de apego, é dada ênfase especial ao aleitamento materno, ao reconhecimento de sinais de al erta do bebê e à al ta precoce.

\section{Panorama em outros países}

A partir da experiência da Colômbia e de sua divulgação, promovida pelo Unicef, vários países do mundo passaram a utilizar o M étodo, internacional mente conhecido como Kangaroo M other Care (KM C). No Brasil adotamos a ter- 
minologia M étodo Canguru, considerando que é uma experiência na qual o pai tem participação ativa e fundamental.

A forma de aplicá-lo e os objetivos buscados são, ainda hoje, muito divergentes e dependem do grau de desenvolvimento do país, da organização da assistência neonatal, de seus valores culturais e de suas crenças e até mesmo da localização geográfica.

O panorama do KM C nos outros países é apresentado a partir dos trabal hos publicadose da troca de experiências nos encontros mundiais (International W orkshop on Kangaroo M other (are) que acontecem a cada dois anos desde 1996. 0 primeiro foi em Trieste, na Itália, e os seguintes na Colômbia, Indonésia, África do Sul e no Brasil, no Rio de Janeiro, o mais recente desses encontros, em novembro de 2004. Durante 0 evento, especialistas e pesquisadores de diversas partes do mundo participam de discussões temáticas em grupos e apresentação de trabalhos.

Os trabalhos publicados, em sua grande maioria, fazem referência, à posição canguru e às suas repercussões para a mãe e para o bebê a partir de experiências individuais de serviços de saúde. Poucas experiências e ou pesquisas publicadas discutem o M étodo Canguru como uma forma de atenção que ultrapassa a posição canguru.

$\mathrm{Na}$ experiência de Israel os bebês ficam em pele a pele com suas mães durante uma hora por dia, no mínimo. Os estudos publicados apontaram o cuidado canguru como uma intervenção que facilita o desenvolvimento sensorial do recém-nascido promovendo o vínculo com a mãe (Feldman et al., 2002).

$\mathrm{Na}$ Índia, em estudos relacionando ganho de peso, al eitamento materno, tempo de internação e cuidado canguru, o tempo de permanência em posição canguru é de cerca de quatro horas, e os resultados demonstram que 0 aleitamento e o ganho ponderal são melhores nos bebês que permanecem em posição canguru (Ramanathan et al., 2001).

U ma experiência publicada na África destaca, além dos benefícios na amamentação, vantagens também quanto à estabilidade fisiológica, diminuição da infecção e aumento do vínculo nas crianças que estão sob o cuidado canguru (Kirsten et al., 2001).

Países como a Itália, Alemanha, França, Reino U nido, Espanha, Dinamarca, Noruega e Sué cia, sem dificuldades para alocação de recursos na atenção à saúde perinatal, o que os diferen- cia em muito da experiência dos países menos favorecidos, apresentaram experiências visando, sobretudo, aumentar o vínculo mãe-filho, desenvolver maior segurança da família no manuseio do seu bebê prematuro e estimular o aleitamento materno (Wallin et al., 2004; Tallandini et al., 2004).

$\mathrm{Na}$ Alemanha, onde o KM C foi introduzido em 1982, com rápida disseminação até 1996, dos 175 serviços de N eonatologia investigados, $91 \%$ já o utilizam (Silva, 2003). Na Inglaterra e na Alemanha, estudos voltados para as repercussões da posição canguru em aspectos fisiológicos como temperatura e oxigenação concluem que a estratégia é segura e deve ser implementada nas unidades neonatais (Bauer et al., 1997; Acolet et al., 1989). Outra possível forma de utilização do M étodo Canguru é o transporte neonatal. Sontheimer et al. (2004) dizem que o transporte entre hospitais pode ser seguro quando feito com o recém-nascido em posição canguru - não havendo efeitos fisiológicos deletérios e apontando vantagens em relação ao transporte em incubadora.

Diferentemente da experiência da Colômbia, na Europa o cuidado canguru está centrado nas unidades neonatais e não são encontradas descrições de práticas domiciliares. Estudos realizados na Itália e na Espanha reforçam o valor para o desenvolvimento do bebê, para o al eitamento e para a formação de vínculo. Os relatos são de tempo curto em contato pele a pele, variando em média de 30 a 90 minutos por dia (M onasterolo et al., 1998).

$\mathrm{Na}$ Escandinávia, onde o índice de desenvolvimento humano é alto, o cuidado canguru também é utilizado nas unidades neonatais, com duração de uma hora por dia. As publicações analisam parâmetros fisiológicos - temperatura e al terações metabólicas (Christensson et al., 1992).

Vários estudos realizados nos Estados U nidos em unidades neonatais comparam o M étodo Canguru com o cuidado tradicional (incubadoras) em relação a parâmetros fisiológicos e concluem que o método é seguro para os be bês e permite maior contato com os pais. Têm sido também estudadas temáticas como benefício da posição canguru em bebês entubados, efeitos no sono, amamentação e desenvolvimento (Legault et al., 1995; Ludington- H oe et al., 2000).

Os trabal hos apresentados no 50 W orkshop M undial do M étodo Canguru discutiram as estratégias de difusão e avaliação do método nos 
diferentes países, as dificuldades geográficas, as barreiras culturais e, fundamentalmente, a falta de recursos financeiros dedicados aos cuidados com a saúde nos países em desenvolvimento.

$\mathrm{Nga}$ et al. (2004) em um estudo realizado no Vietnã descreveram a estratégia de treinamento das equipes de saúde e da difusão da atenção médica, utilizando-se do Cuidado Canguru em todo o país, como uma ação para diminuir a morbimortalidade neonatal.

\section{Método Canguru no Brasil}

O H ospital Guilherme Álvaro, em Santos, São Paulo, foi o primeiro a utilizar o cuidado canguru, no Brasil, em 1992; no ano seguinte a metodologia foi adotada pelo Instituto $M$ aterno Infantil de Pernambuco (IMIP), na cidade de Recife, em Pernambuco (Prochnik \& CarvaIho, 2001).

A partir dessas experiências, vários outros hospitais brasileiros começaram a utilizar a posição canguru, porém nem sempre com metodologia e critérios adequados (Oliveira, 2004). Em março de 1999, por iniciativa do BNDES, foi organizada uma Conferência $\mathrm{N}$ acional sobre o M étodo Canguru, no Rio de Janeiro, na qual foram apresentadas as mais diversas experiências sobre a utilização do método nos diferentes estados brasileiros.

Com a intenção de padronizar esse tipo de cuidado, melhorando a eficiência e a eficácia do M étodo Canguru, a Área Técnica de Saúde da Criança do M inistério da Saúde constituiu uma equipe multiprofissional, formada por consultores com experiência profissional e acadêmica nos diferentes aspectos que compõem o complexo universo da Terapia Intensiva N eonatal, desde 0 atendimento em sala de parto até o seguimento dos egressos (M S, 2002).

0 trabal ho inicial de discussão conceitual sobre o M étodo Canguru - origem, definição, vantagens e dificuldades - levou ao entendimento da sua importância para a assistência neonatal e ao amadurecimento de uma proposta nacional de utilização, que não deveria ser considerada uma técnica a mais, porém numa iniciativa contextualizada em uma proposta mais ampla de humanização. Foi então elaborada a N orma de Atenção H umanizada ao Recém-N ascido de Baixo Peso - M étodo Canguru, lançada em dezembro de 1999 e publicada através da Portaria M inisterial no. 693 de 5/7/2000. O M étodo Canguru foi assim incluí- do na Política Governamental de Saúde Pública, no Brasil, como um procedimento de assistência médica, com inclusão na tabela de procedimentos do SUS.

\section{Estratégias de disseminação}

O Programa de Disseminação, desenvolvido e coordenado pelo M inistério da Saúde em parceria com o BNDES e com a Fundação ORSA, incluiu a sensibilização de gestores estaduais e municipais através de cinco seminários em diferentes regiões do País.

Como etapa central no processo de disseminação desta política pública, encontramos um amplo programa de capacitação dos profissionais das diferentes especialidades que lidam com o recém-nascido, sua mãe e sua família. 0 programa de treinamento teórico-prático foi dirigido aos profissionais de nível superior, inseridos na assistência à díade mãe-bebê: médicos, enfermeiros, fisioterapeutas, fonoaudiólogos, psicólogos, terapeutas ocupacionais, nutricionistas e assistentes sociais.

Para a realização dos cursos de capacitação foi elaborado e publicado um manual técnico. Este manual apresenta e discute a norma, além de trazer uma ampla fundamentação teórica acerca das especificidades e necessidades especiais do recém-nascido de baixo peso (RNBP), de sua família e de toda a equipe responsável pelo atendimento.

Foram também selecionados Centros $\mathrm{Na}$ cionais de Referência para a Atenção Humanizada ao Recém- $\mathrm{N}$ ascido dentre unidades hospitalares com características organizacionais e estruturais compatíveis com a proposta de treinamento estabelecida, elegendo, como prioridade de implantação da metodologia, as maternidades pertencentes ao Sistema de Referência de Gestação de Alto Risco do M inistério da Saúde.

Os primeiros centros de capacitação foram - Instituto M aterno Infantil de Pernambuco (IMIP), em Recife; o H ospital Universitário da Universidade Federal do $M$ aranhão, em São Luís; a Maternidade Escola Assis Chateaubriand da U niversidade Federal do Ceará, em parceria com a M aternidade César Calls, em Fortaleza; a Secretaria M unicipal de Saúde do Rio de Janeiro; o Hospital Universitário da Universidade Federal de Santa Catarina, em Florianópolis. Visando atender à crescente demanda, no segundo ano do treinamento foram 
definidos dois novos centros de referências: 0 Hospital Regional de Taguatinga, no Distrito Federal, e o H ospital Geral de Itapecerica da Serra, em São Paulo.

0 processo de capacitação ofereceu aos profissionais a possibilidade de reflexão acerca de sua prática diária e de construção de uma prática assistencial pautada no cuidado. Segundo Boff (1999), cuidado representa uma atitude de ocupação, de envolvimento e de responsabilização com o outro. A partir desta ótica, a humanização proposta abrange atenção individualizada ao bebê e sua família, adequação do ambiente, cuidados com o cuidador. Técnicas de manuseio, vigilância quanto aos sinais de risco, estimulação sensorial positiva através do contato pele a pele e 0 acompanhamento do crescimento e do desenvolvimento dessas crianças são abordadas nesse curso. A metodologia é calcada em aulas expositivas, leituras de textos, dinâmica de grupo, dramatizações, debates e exercícios práticos.

No período de agosto de 2000 a dezembro de 2002, foram realizados 59 cursos com um total de 1.850 profissionais, de 269 maternidades, capacitados no método (MS, 2003).

\section{A aplicação da norma}

A N orma brasileira deixa bem estabelecida a diferença entre M étodo Canguru e Posição Canguru. Segundo o M inistério da Saúde (2002), M étodo Canguru é um tipo de assistência neonatal que implica contato pele a pele precoce entre a mãe e o recém-nascido de baixo peso, de forma crescente e pelo tempo que ambos entenderem ser prazeroso e suficiente, permitindo uma maior participação dos pais no cuidado a seu recémnascido e o envolvimento da família. A Posição Canguru consiste em manter o RN de baixo peso, ligeiramente vestido, em decúbito prono, na posição vertical, contra o peito de um adulto.

0 M étodo Canguru é mais abrangente e ultrapassa a Posição Canguru. M uitas vezes o bebê ainda não tem estabilidade clínica para poder ser colocado em posição canguru, mas as ações que envolvem o método já foram iniciadas através do acolhimento à família, da construção de rede social e da atenção individualizada ao bebê.

O Programa, no Brasil, não tem como objetivo a substituição de incubadora ou de qualquer outra tecnologia ou recursos humanos e sim a promoção de uma mudança institucional na busca de atenção à saúde, centrada na humanização da assistência e no princípio de cidadania da família (MS, 2002).

Venâncio \& Almeida (2004), em seu trabaIho de revisão, citam que a associação de medidas protetoras como adequação postural, atenuação de ruído eluminosidade, o contato pele a pele e a participação dos pais no cuidado trazem novas perspectivas para o desenvolvimento neurocomportamental de bebês egressos de UTI Neonatal.

A mudança na forma do cuidado neonatal proposta pelo M étodo Canguru está baseada em quatro fundamentos básicos: acolhimento do bebê e sua família; respeito às individualidades; promoção do contato pele a pele o mais precoce possível; envolvimento da mãe nos cuidados do bebê (Lamy, 2003).

Com sua aplicação dividida em três etapas, a primeira destas está focada nos aspectos psico-afetivos que cercam o nascimento de um recém-nascido prematuro ou gravemente enfer$\mathrm{mo}$, envolvendo 0 atendimento de uma equipe multiprofissional através de intervenção interdisciplinar. Neste momento, aos cuidados técnicos relativos ao atendimento do $\mathrm{RN}$ inclui-se o cuidado à mãe e à família, no sentido não só de orientar quanto às condições de saúde da criança, mas também de estimular o livre acesso dos pais à UTI favorecendo o contato tátil com o RN, assim como a co-participação da mãe nos cuidados com o bebê, promovendo um processo contínuo na formação da ligação afetiva entre bebês e seus pais.

0 conhecimento sobre estes aspectos vem despertando interesse de vários pesqui sadores, como Klaus et al. (2000), que, na revisão de 17 estudos sobre 0 assunto, demonstraram que as primeiras horas e dias após o parto são um período facilitador da vinculação mãe-bebê.

Winnicott (1990) considera que o holding (relação direta entre os pais e o bebê, no sentido de reter, conter, sustentar, segurar) é indispensável para o desenvolvimento inicial do potencial do bebê, abrangendo tudo aquilo que uma mãe faz por seu bebê. No caso dos RN prematuros, na UTI, poderíamos dizer: tudo aquilo que é possível para esta mãe fazer por seu bebê.

Esta etapa exige da equipe neonatal instrumentos que permitam reflexão sobre suas práticas junto do RN e a sua família, não só quanto aos aspectos psicossociais, mas também aos cuidados com o ambiente físico da UTI, questão contemporânea na discussão sobre a boa prática neonatal. 
Tem sido muito estudado o impacto do ambiente de terapia intensiva, repleto de estímulos estressantes e de procedimentos invasivos, que, embora essenciais para a sobrevivência do RN, têm impacto negativo no seu desenvolvimento (H oath, 2001; Bhutta \& Anand, 2002). Importantes estratégias visando minimizar os efeitos do excesso de som, luminosidade e estímulos táteis vêm sendo utilizadas.

No Brasil, a proposta de humanização no cuidado neonatal recebeu influência da Pediatria do Desenvolvimento e do N ewborn D evelopment Care and Assessment Program (NID(AP), que propõem uma abordagem de cuidados individualizados, por meio da atuação interdisciplinar, favorecendo o desenvolvimento do RN e agindo como facilitador do vínculo mãe-bebê (M S, 2002). Os estudos de Als et al. (2004) mostram que os prematuros que receberam cuidados individualizados, isto é, modificação e adaptação dos cuidados fornecidos em resposta ao reconhecimento individual de suas necessidades, apresentaram melhor desempenho no desenvolvimento cortical, observado através de uma maior auto-regulação e comportamento calmo ao longo de intervenções.

O M étodo Canguru, conforme apresentado em suas diretrizes operacionais, tem perspectiva interdisciplinar revelando (...) um momento de amadurecimento da assistência neonatal em que se compreende que o tratamento do RN envolve muito mais do que apenas a utilização de procedimentos e técnicas (MS, 2002).

A segunda etapa acontece após a estabilidade clínica do bebê e se caracteriza pelo acompanhamento contínuo da mãe na enfermaria canguru. 0 enfoque desta etapa é para a efetiva participação da mãe nos cuidados do bebê e no seu desenvolvimento psicoafetivo, base das interações entre a criança e seus pais.

A formação do vínculo não é um acontecimento imediato, ocorre por meio de interações sucessivas. Quanto mais oportunidades de interação entre mãe e bebê mais forte será o vínculo e, conseqüentemente, melhor a resposta materna às necessidades do filho e menor a probabilidade de negligência, maus-tratos e abandono.

Os trabal hos de Charpak (2001) e os de Anderson et al. (2004) também mostraram que 0 contato pele a pele precoce entre a mãe e o RN favorece o senso de controle (domínio) e autoconhecimento, resultando numa maior confiança e melhor vínculo mãe-bebê, fator preditivo para uma amamentação duradoura e cuidados adequados.
A terceira etapa objetiva a continuidade da assistência através do acompanhamento ambulatorial, individualizado, buscando observar 0 desenvolvimento global do bebê, através de um programa de acompanhamento (follow up).

A importância da identificação precoce de fatores de risco para alterações no desenvolvimento é largamente descrita na literatura, através de protocolos, screenings e testes avaliativos específicos para o acompanhamento de bebês de risco.

Vários estudos confirmam a importância de programas interdisciplinares preventivos de follow up de prematuros, especialmente no primeiro ano de vida, com o intuito de promover o desenvolvimento da criança e minimizar as possíveis seqüelas de saúde do período neonatal (Brofenbrenner, 1996; Charpak, 2001; Nobre et al., 2004; Oliveira, 2002).

\section{O Método Canguru como estratégia de humanização em saúde}

É importante registrar que, ao final da década de 1990, quando ficou mais evidente o processo de implantação da política pública direcionada ao atendimento de recém-nascidos de baixo peso, já encontrávamos, na pauta dos movimentos feministas, as propostas de humanização em relação ao parto e aos direitos reprodutivos das mulheres (Gomes, 2004). Este conjunto de propostas estava, entretanto, mais voltado para as questões referentes ao parto e nascimento.

A proposta da Atenção H umanizada ao Recém-Nascido de Baixo Peso - M étodo Canguru, por sua vez, amplia seu foco para a internação do bebê e para as situações de risco que dificultam o desenvolvimento e a relação mãe-bebê.

$\mathrm{N}$ a leitura dos documentos do M inistério da Saúde é possível perceber um cuidado para que esta diretriz não seja uma proposta de substituição de tecnologia e sim uma nova abordagem, muito mais ampla, (...) que requer dos profissionais conhecimentos acerca das particularidades físicas e biológicas e das necessi dades especiais de cuidados técni cos e psicológi cos da gestante, da mãe, do recém-nascido de baixo peso e de toda a família. Abrange também a equipe de profissionais responsável por esse atendimento, buscando motivá-la para mudanças importantes em suas ações como cuidadores (M S, 2002).

A Atenção Humanizada ao Recém-N ascido de Baixo Peso - M étodo Canguru é, portanto, uma estratégia de qualificação do cuidado pau- 
tada na atitude dos profissionais de saúde diante do bebê e de sua família a partir de um conceito de assistência que não se limita ao conhecimento técnico específico. Sob essa perspectiva, ao proporcionar mais contato entre o bebê e sua mãe, seu pai, irmãos e avós, busca construir uma rede social de apoio para a mãe e contribuir para a diminuição dos efeitos negativos da internação neonatal.

Para Deslandes (2004) o termo "humanização" vem sendo utilizado com freqüência no âmbito da saúde, para qualificar as formas de assistência que valorizem a qualidade do cuidado do ponto de vista técnico, associadas ao reconhecimento dos direitos do paciente, de sua subjetividade e referências culturais, implicando ainda a valorização do profissional.

Não é, portanto, uma mudança fácil. Concordamos com Deslandes (2004) que não se muda uma cultura de assistência unicamente com capacitações dirigidas aos profissionais, que se faz necessário investimento sério na formação dos profissionais de saúde, para que seja possível fortalecer idéias outrora consideradas utópicas ou fora do "papel" da assistência. A Atenção Humanizada ao Recém- $N$ ascido de Baixo Peso - M étodo Canguru caminha em direção à superação da clássica fragmentação entre ações de humanização e ações assistenciais.

Com freqüência a humanização em saúde nos é apresentada como um desafio que parece ser de responsabilidade exclusiva da ação do profissional dirigida aos usuários dos serviços de saúde. Contudo não podemos e não devemos esquecer que a humanização também deve ser estendida ao profissional através de ações que envolvam seu processo de trabalho.

\section{Considerações finais}

O M étodo Canguru se encontra hoje em plena expansão no mundo. A cada dois anos, durante o encontro mundial, é maior o número de países que trazem suas experiências. As diferenças socioculturais, econômicas e geográficas têm levado a diferentes objetivos e aplicações. Dessa forma, o método é descrito tanto como o único cuidado possível, a exemplo de algumas comunidades africanas que não têm acesso aos serviços de saúde, quanto como uma importante ferramenta para a humanização quando toda a tecnologia é disponível.

A análise do processo de implantação da Atenção Humanizada ao Recém- $\mathrm{N}$ ascido de
Baixo Peso - M étodo Canguru pelo M inistério da Saúde nos permite mapear uma experiência consideravel mente mais ampla do que a dos países que adotaram ou discutem o M étodo Canguru em países de extrema dificuldade de acesso à assistência neonatal. N essas regiões, 0 M étodo Canguru é apontado como estratégia de substituição de tecnologia (pela ausência ou insuficiência quantitativa de leitos levando a uma imperiosa necessidade de redução do tempo de internação neonatal) e de incentivo ao Aleitamento M aterno. Por outro lado, a experiência brasileira também é mais ampla do que aquela encontrada nos países desenvolvidos, nos quais também encontramos os elementos ligados às intervenções no ambiente e na forma do cuidado neonatal, incluindo aqui o incentivo ao contato pele a pele o mais prolongado possível como uma das práticas envolvidas.

Vale ressaltar que o tempo de realização da posição canguru diverge muito nas diferentes experiências. $\mathrm{Na}$ Europa, Estados U nidos e $\mathrm{Ca}$ nadá existe uma tendência de determinação do período ideal, em geral poucas horas em um turno do dia. $\mathrm{Na}$ Colômbia, onde o cuidado é predominantemente domiciliar, as mães são orientadas a permanecer com o bebê 24 horas em posição canguru. No Brasil a recomendação é incentivar e encorajar os pais a praticarem o método pelo maior tempo possível, sem que seja determinado número de horas ou um turno específico para essa prática.

Entretanto, os desafios ainda são muitos. Entendemos que a plena incorporação do M é todo Canguru pelas maternidades brasileiras requer estratégias comprometidas com educação permanente de toda equipe envolvida, da mesma forma como ocorre em outros aspectos do cuidado neonatal. Além disso, reiteramos a importância de estudos que avaliem a implantação da Atenção H umanizada ao Recém-N ascido de Baixo Peso e seu impacto nos resultados neonatais em nosso país.

Por fim, ressaltamos que esses desafios não podem ser descontextualizados da situação atual do atendimento perinatal no setor público brasileiro, especialmente dos aspectos ligados à assistência obstétrica e neonatal de risco. Dificuldades de acesso, fragmentação entre a assistência pré-natal e a atenção ao parto, práticas assistenciais inadequadas e superlotação nas maternidades estão bem documentadas em diferentes regiões brasileiras e é esse o cenário no qual as estratégias de humanização estão colocadas. 
Nesse sentido, encontramos apoio na Política N acional de H umanização do M S proposta a partir de 2003 (MS, 2004). Assumir que, muito mais que um mero "programa", a humanização deve ser eixo articulador de todas as práticas em saúde é tarefa imprescindível para ges- tores e trabal hadores nas diferentes esferas do sistema de saúde. As reflexões e experiências dos profissionais que estão aplicando o M étodo Canguru a partir de uma perspectiva ampliada de humanização podem e devem ser aproveitadas para essa tarefa.

\section{Colaboradores}

0 trabalho de elaboração do artigo foi desenvolvido de forma conjunta pelos autores.

\section{Referências bibliográficas}

Acolet D, Sleath K \& Whitelaw A 1989. Oxygenation, heart rate and temperature in very low birth weight infants during skin-to-skin contact with their mothers. Acta Paediatr Scand 78:189-193.

Als $\mathrm{H}$ et al. 2004. Early experience alters brain function and strutcture. Pediatrics 113(4): 846-857.

Anderson GC et al. 2004. Early skin-to-skin contact for mothers and their healthy newborn infants. The Cochrane Library, issue 2, 2004. Disponível em <http: //cochrane.bireme.br/cochrane/show.php?db=reviews>. Acessado em 4.10.04

Bauer K, Uhrig C, Sperling P, Pasel K, Wieland C \& Versmold HT 1997. Body temperatures and oxygen consumption during skin-to-skin (kangaroo) care in stable preterm infants weighing less than 1500 grams. J Pediatrics 130:240-244.

Bhutta AT \& Anand KJS 2002. Vulnerability of the developing brain neuronal mechanisms. Clinics in Perinatology 29:357-372.

Boff L 1999. Saber cuidar: ética do humano - compaixão pela terra. Ed. Vozes. Petrópolis.

Botero HC 2000. Observar um "bebé canguro": el útero para gestar la relación madre-bebé, pp.15-28. In NR de Polanco (org.) - Observación de Bebés. Editora Plaza e Valdés, M éxico. 
Brofenbrenner U 1996. A ecologia do desenvolvimento humano e experimentos naturais e planejados. Artes Mé dicas, Porto Alegre.

Browne JV 2005. Early relationship environments: physiology of skin contact for parents and their preterm infants. Clinics in Perinatology 31(2):287-298.

Charpak N, Calume ZF \& H amel A 1999. 0 método mãe canguru - pais e familiares de bebês prematuros podem substituir as incubadoras. Chile: M cGraw Hill, edição brasileira.

Charpak N 2001. Kangaroo mother care in developing countries. 5th World Congress of Perinatal M edicine: 1023-1027.

Christensson K, Siles C, M oreno L, Belaustequi A, De La Fuente $\mathrm{P}$, Lagercrantz $\mathrm{H}$ et al. 1992. Temperature, metabolic adaptation and crying in healthy full-term newborns cared for skin-to-skin or in a cot. Acta Paediatr 81: 488-493.

Deslandes SF 2004. Análise do discurso oficial sobre a humanização da assistência hospitalar. Ciência e Saúde Coletiva 9(1):7-14.

Feldman R, Eidelman A, Sirota L \& Weller A 2002. Comparison of skin-to-skin (Kangaroo) and traditional care: parenting outcomes and preterm infant development. Pediatrics 110:16-26.

Gomes M ASM 2002. Assistência neonatal na Secretaria M unicipal de Saúde do Rio de Janeiro: uma análise do período 1995-2000. Tese de doutorado. Instituto Fernandes Figueira, Fundação Oswaldo Cruz, Rio de Janeiro.

Gomes M ASM 2004. Organização da Assistência Perinatal no Brasil, pp. 21-48. In M EL M oreira, JM A Lopes, $M$ Carvalho (orgs.). 0 recém-nascido de alto risco: teoria e prática do cuidar. Coleção Criança, Mulher e Saúde. Fiocruz. Rio de Janeiro.

H oath SB 2001. The skin as a neurodevelopmental interface. N eoReviews 2(12):292-301.

Kirsten GF, Bergman NJ \& Hann KM 2001. Kangaroo mother care in the nursery. Pediatric Clinics of $\mathrm{N}$ orth America 48: 443-452.

Klaus M H, Klaus PH \& Kennell JH 2000. Vínculo: construindo as bases para um apego seguro e para a independência. Artes M édicas, Porto Alegre.

Lamy ZC 2000. U nidade neonatal: um espaço de conflito e negociações. Tese de doutorado. IFF/Fiocruz, Rio de Janeiro.

Lamy ZC 2003. M etodologia Canguru: facilitando o encontro entre o bebê e sua família na U nidade N eonatal, pp. 141-156. In MEL Moreira, NA Braga, DS M orsch (orgs.). Quando a vida começa diferente. Coleção Criança, M ulher eSaúde. Fiocruz, Rio de Janeiro.

Lansky S, França E \& Leal M C 2002. M ortalidade perinatal e evitabilidade: revisão de literatura. Revista de Saúde Pública 36(6): 759-772.

Legault M \& Goulet C 1995. Comparison of Kangaroo and traditional methods of removing preterm infants from incubators. JOGN N 24: 501-506.

Ludington-H oe SM, N guyen N, Swinth JY \& Satyshur RD 2000. Kangaroo care compared to incubators in maintaining body warmth in preterm infants. Biol Res N urs 2(1): 60-73.

M inistério da Saúde 2002. Atenção humanizada ao recémnascido de Baixo Peso - M étodo $M$ ãe-Canguru - M anual Técnico. Brasília.

M inistério da Saúde 2003. Relatório de gestão da Secretaria de Políticas de saúde. Período 2000-2003.
M inistério da Saúde 2004. Política Nacional de H umanização: a humanização como eixo norteador das práticas de atenção e gestão em todas as Instâncias do SUS. Editora MS. Braślia.

M onasterolo RC, Beneitez MJ, Olive M M R, M artinez MJ \& Papi AG 1998. "Kagaroo method" in the care of premature infants admitted to a neonatal intensive care unit. An Esp Pediatr 49(5): 495-498.

N ga TN, Chi LK, H oa TT \& Binh NT 2004. Kangaroo mother care diffusion in Vietnam. 5o W orkshop Internacional sobre o M étodo Canguru. Rio de Janeiro, Brasil, 8-12 de novembro, 2004.

Nobre FDA et al. 2004. Risco neonatal e desenvolvimento infantil avaliado através da escala de desenvolvimento do comportamento da criança: 10 ano de vida (EDCC). Revista Paulista de Pediatria 22: 35.

Oliveira M CB 2002. A valiação do crescimento de recémnascidos de risco egressos de UTIs neonatais - um estudo prospectivo e multicêntrico. Dissertação de mestrado. IFF/Fiocruz, Rio de Janeiro.

Oliveira ND 2004. Como o Brasil trabalha o método canguru. Disponível em <www.metodocanguru.org.br/ historico>. Acessado em 29/08/04.

Organização M undial de Saúde 2004. M étodo Madre Canguro: Guia Práctica. Genebra.

Prochnik M \& Carvalho M R 2001. M étodo M ãe-Canguru de Atenção ao Prematuro. BNDES, Rio de Janeiro.

Ramanathan K, Paul VK, Deorari AK Taneja U \& George $G$ 2001. Kangaroo $M$ other $C$ are in very low birth weight infants. Indian Journal of Pediatrics 68(11): 1019-1023.

Santoro Jr W \& Santoro A 2002. Reações psicológicas e processo adaptativo de pais de recém-nascidos prétermo e de muito baixo peso em unidades de terapia intensiva neonatal (UTIN). Revista Paulista de Pediatria 20(2):95-101.

Silva OPV 2003. Análise descritiva do desenvolvimento de recém-nascidos prematuros que participaram do programa M étodo M ãe-Canguru. Dissertação de mestrado. Universidade M ackenzie, São Paulo.

Sontheimer D, Fischer CB \& Buch KE 2004. Kangaroo transport instead of incubator transport. Pediatrics 113:920-923.

Tallandini M A, Scalembra C, Corbatto P, Strain T \& Demarini S 2004. The psychological impact of kangaroo mother care on mother-infant bonding in preterm delivery. 50 W orkshop Internacional sobre o M étodo Canguru. Rio de Janeiro, Brasil, 8-12 de novembro, 2004.

Venâncio SI \& Almeida H 2004. M étodo M ãe Canguru: aplicação no Brasil, evidências científicas e impacto sobre aleitamento materno. Jornal de Pediatria 80(5 Supl): S173-S180.

Wallin L 2004. Kangaroo mother care in Sweden. Preliminary results of a trial on facilitation support for guideline implementation. 5o Workshop Internacional sobre o M étodo Canguru. Rio de Janeiro, Brasil, 8-12 de novembro.

Winnicott DW 1990. 0 ambiente e o processo de maturação. Artes M édicas, Porto Alegre.

Artigo apresentado em 16/03/2005

Aprovado em 25/04/2005

Versão final apresentada em 23/05/2005 